\title{
Avoiding Backlash or Proving One's Manhood? Beliefs About Gender Differences in Negotiation
}

\author{
Jens Mazei ${ }^{1} \mathbb{D}$. Julia B. Bear ${ }^{2} \mathbb{D}$. Joachim Hüffmeier ${ }^{1} \mathbb{D}$
}

Accepted: 18 August 2021 / Published online: 3 September 2021

(c) The Author(s) 2021

\begin{abstract}
Gender differences in negotiation are typically explained by processes that concern women (e.g., women anticipate backlash for assertive behavior). Research has begun to suggest that processes that concern men (e.g., men want to be seen as "real" men) also help to explain gender differences. However, these 2 approaches typically remain disconnected. Thus, we examined both types of processes in 3 studies examining people's beliefs about the causes of gender differences in negotiation (total $N=931$ ). Our studies showed that people endorsed to a similar, and sometimes even greater, extent processes that concern men as underlying gender differences in negotiation. Moreover, people's beliefs about the causes of gender differences in negotiation were related to perceptions of the effectiveness of different diversity initiatives (i.e., interventions to reduce inequities) and willingness to support them.
\end{abstract}

Keywords Negotiation $\cdot$ Masculinity $\cdot$ Gender $\cdot$ Sex $\cdot$ Gender gap

\section{General Introduction}

A great deal of research has been devoted to the understanding of causes-in other words, underlying processes — of gender differences in negotiation (e.g., Kray et al. 2001; Stuhlmacher and Linnabery 2013). Past research has documented processes that hinder women, in particular, from negotiating effectively (e.g., Amanatullah and

Jens Mazei

jens.mazei@tu-dortmund.de

Julia B. Bear

julia.bear@stonybrook.edu

Joachim Hüffmeier

joachim.hueffmeier@tu-dortmund.de

1 Department of Psychology, TU Dortmund University, Emil-Figge-Strasse 50, 44227 Dortmund, Germany

2 College of Business, Stony Brook University, Harriman Hall 254, Stony Brook, NY 11794 , USA 
Morris 2010; Bowles et al. 2007). Yet, recent empirical (Kray and Haselhuhn 2012; Netchaeva et al. 2015) and theoretical (Kennedy and Kray 2015; Mazei et al. 2021; Miller 2013) advances suggest that processes that concern women may not be the full story: men are often anxious about not appearing "man enough" (Gilmore 1990; Vandello and Bosson 2013) and, hence, become especially competitive in negotiations (Netchaeva et al. 2015). However, research tends to focus either on processes that concern women or, by contrast, on processes that concern men (see Kennedy and Kray 2015, or Kray et al. 2001, for examples of exceptions). In this way, a comprehensive understanding of gender differences in negotiation is lacking, and researchers are left unguided as to whether processes that concern men represent a particularly worthwhile research avenue, especially in comparison to processes that concern women. Thus, we explored people's beliefs regarding processes concerning both men and women in negotiation.

Gaining insight into people's beliefs, which capture what people think is true (Gilbert 1991; Markóczy 1997), is relevant for two reasons: first, beliefs can be an important source of information as they are often based on actual events. For example, beliefs about the characteristics of groups result from observations of their actual activities in society (Eagly and Steffen 1984; Koenig and Eagly 2014). Second, beliefs influence "perceptions, interpretations, and reactions, and in so doing create "self-fulfilling prophecies" (Ross et al. 2010, p. 4; see also Manea et al. 2020). Altogether, beliefs are relevant given their informational value concerning the causes of gender differences and their practical consequences.

Hence, we provide insight into people's beliefs about the causes of gender differences in negotiation. Hereby, we increase the understanding of processes that concern men specifically by beginning a line of inquiry concerning their role in the emergence of gender differences (see also Kennedy and Kray 2015; Netchaeva et al. 2015), relative to processes that concern women (e.g., Stuhlmacher and Linnabery 2013). Moreover, we explore whether men and women have different beliefs about the causes of gender differences in negotiations (see also Bosson et al. 2021). Certain processes, such as discrimination, can be subtle (Jones et al. 2016), so that people who are not subject to such a process (e.g., men) may overlook them (Swim et al. 2001; Weaver et al. 2010). Thus, examining whether women and men differ in their beliefs provides insight into the antecedents of people's beliefs (e.g., being oneself subject to a certain process; but see Bosson et al. 2021). Finally, we examine the potential consequences of these beliefs by examining their relationships with people's appraisals of different diversity initiatives and their willingness to support them (see also Manea et al. 2020). Thus, our findings also have practical implications for promoting diversity goals in organizations (e.g., Leslie 2019).

\subsection{Processes Concerning Women}

Women often negotiate less frequently (Kugler et al. 2018; Small et al. 2007) and less successfully than men (Bowles et al. 2005; Mazei et al. 2015). These gender differences are typically explained (e.g., Bear and Babcock 2017; Kugler et al. 2018) with social role theory (Eagly 1987): people observe that men and women often 
engage in different activities - for example, women are more likely to take care of children (Croft et al. 2015; Eagly and Carli 2007). As a result, people believe that women are more communal (e.g., cooperative) but less agentic (e.g., competitive) than men (Eagly et al. 2020; Eagly and Steffen 1984; Rudman et al. 2012). These beliefs are captured in the concept of gender roles: "the collection of both descriptive and injunctive expectations associated with women and men" (Eagly and Karau 2002, p. 574). The injunctive component can be further divided into prescriptions and proscriptions ("how men and women should behave" and "should not behave"; Rudman et al. 2012, p. 166).

Gender roles matter because people often internalize them (Eagly and Wood 2012; Wood and Eagly 2010), and, as a result, exhibit behaviors that are in line with their gender role (Croft et al. 2015; Twenge 1997). Moreover, others react negatively to women and men who deviate from their gender roles (Amanatullah and Tinsley 2013; Heilman and Wallen 2010), a reaction known as backlash (Rudman 1998). As such, people typically behave in ways consistent with their gender role to avoid backlash (Amanatullah and Morris 2010; Rudman and Fairchild 2004).

Women can be disadvantaged in negotiations because agentic behaviors increase economic outcomes (Hüffmeier et al. 2014; Kulik and Olekalns 2012). However, when women show agentic negotiation behaviors, they risk incurring backlash (Amanatullah and Tinsley 2013; Bowles et al. 2007). Altogether, there is an incongruity (Eagly and Karau 2002) between women's communal gender role and the agency of an economically successful negotiator (e.g., Kugler et al. 2018; Stuhlmacher and Linnabery 2013). Still, women certainly are no less effective negotiators per se (Bowles et al. 2005; Kray et al. 2001): for instance, women negotiate more ethically than men (e.g., Kray and Haselhuhn 2012), which is likely to enhance trust (cf. Kennedy and Kray 2015; Lee et al. 2017) and, hence, achieve joint gains in integrative negotiations (Kong et al. 2014; but see Calhoun and Smith 1999). Women can also use strategies to overcome their disadvantages (e.g., Bear and Babcock 2017; Bowles and Babcock 2013) or may even use their femininity to their advantage (Kray et al. 2012). In sum, negotiation research has illuminated processes that concern women (Haselhuhn and Kray 2012; Miller 2013), which is clearly valuable. Yet, explaining gender differences only by processes that concern women also has limitations: in 2 meta-analyses that used role incongruity among women as a theoretical lens (Kugler et al. 2018; Mazei et al. 2015), much variability in gender differences was left unaccounted for (Lee et al. 2017; Mazei et al. 2021).

\subsection{Processes Concerning Men}

Processes that concern men may also help to explain gender effects in negotiation (e.g., Cantrell and Butler 1997; Kennedy and Kray 2015; Miller 2013). For example, Netchaeva et al. (2015) found that men, but not women, experienced a threat and behaved particularly assertively when they negotiated with a female, but not a male, hiring manager. Moreover, Kray and Haselhuhn (2012) found that processes that concern men (i.e., the perception that negotiating is a masculine activity) help 
to account for gender differences in the usage of unethical negotiation tactics (for further relevant work, see Haselhuhn et al. 2014; Kray et al. 2001; Lee et al. 2017).

This aforementioned negotiation research is typically grounded in the precarious manhood thesis (Vandello and Bosson 2013; Vandello et al. 2008), which argues that men often feel the need to show that they are "real" men (Gilmore 1990). In turn, being considered a "real" man requires confirmation by other people (Bosson and Vandello 2011; Vandello et al. 2008). Men's status as a "real" man is also easily questioned, so that men frequently experience anxiety (Vandello and Bosson 2013; Vandello et al. 2008) and aim to "prove" their manhood (e.g., Berke et al. 2017; Bosson et al. 2009). Mazei et al. (2021) integrated these insights into a model concerning the negotiation context, which proposes that men perceive their negotiation performance as affecting their status as a "real" man (Kennedy and Kray 2015; Kray and Haselhuhn 2012), which then shapes their negotiation behaviors (Miller 2013; Netchaeva et al. 2015). Many propositions of their model, however, still await empirical testing.

\subsection{The Current Research}

Extant work typically focuses either on processes that concern women or on processes that concern men-that is, the two approaches remained disconnected (but see Kennedy and Kray 2015; Kray et al. 2001). This is problematic as there remains uncertainty regarding the relative importance of the different processes: although processes concerning men may in principle exist, it could be that they play only a minor role in the emergence of gender differences in comparison to processes that concern women. If true, it may not be advisable to invest more resources into the study of processes concerning men and into interventions that address them. By contrast, if processes concerning men play an equal role, perhaps more attention should be devoted to them. Hence, we conducted 3 studies on people's beliefs about the causes of gender differences in negotiation that simultaneously consider processes that concern both women and men.

A "belief is (...) the mental state or function of cognising reality" (James 1889, p. 321; see Gilbert 1991). Thus, beliefs capture what people think is true (Gilbert 1991; Markóczy 1997). Beliefs can have informational value: Social role theory holds that "gender role beliefs (...) are not arbitrary or random" (Wood and Eagly 2010, p. 633), but result from observations of women's and men's activities in society (Eagly and Steffen 1984; Koenig and Eagly 2014). Hence, exploring beliefs is a useful starting point for a comprehensive examination of the causes of gender differences in negotiation. Moreover, beliefs have consequences, regardless of their accuracy: via confirmation bias (Nickerson 1998) and self-fulfilling prophecies (Ross et al. 2010), people act on their beliefs. Hence, research has begun to shed light on beliefs related to gender issues in negotiation (Kray et al. 2001; Manea et al. 2020).

People are likely to believe in processes that concern women (independent of their beliefs in processes that concern men) following everyday observations (Koenig and Eagly 2014). People, and women, in particular, report experiences involving prejudice toward women or sexism occurring as frequently as each week (Swim et al. 
2001). Moreover, processes that concern women play a prominent role in research (e.g., Miller 2013; Rudman and Fairchild 2004), which is often disseminated to the public. Relatedly, processes concerning women, such as discrimination, are popular topics in the media (e.g., Auletta 2014). All of these experiences could lead people to endorse processes concerning women.

However, people may also endorse processes concerning men: People typically consider negotiating to be a "man's game" (Bowles and Kray 2013, p. 4). Following this "masculine" perception of negotiations (Kray and Thompson 2005; Kray et al. 2001), people might believe that processes concerning men cause gender differences in negotiation. Moreover, people from various cultures (Gilmore 1990) perceive manhood as easily questioned and difficult to maintain (i.e., as "precarious"; Bosson and Vandello 2011; Vandello et al. 2008). This suggests that people may frequently observe men aiming to demonstrate their manhood. Finally, Rudman and Fairchild (2004; see also Bosson et al. 2006) found that men feared backlash more so than women. As certain processes (e.g., fear of backlash) may be more pronounced among men, people may also endorse processes concerning men.

Altogether, people likely endorse processes that concern both men and women. Yet, the relative strength of these beliefs is unclear. We aim to answer this research question (RQ; see Studies 1-3):

- $R Q$ 1: To what extent do people believe that processes concerning men versus women underlie gender differences in negotiation?

We also explored gender differences in beliefs about the causes of gender differences in negotiation. Certain processes, such as discrimination, can be subtle (Jones et al. 2016). In fact, women report more experiences of sexism (Swim et al. 2001), whereas men may be more aware of the precarious nature of manhood (Weaver et al. 2010; but see Bosson et al. 2021; Vandello et al. 2008). Consequently, women, more so than men, might believe in processes that concern women, and vice versa. Yet, both women and men endorse stereotypical gender roles and react with backlash to role deviations (Eagly et al. 2020; Rudman and Phelan 2008). Therefore, it could also be that women and men do not differ in their beliefs. In sum, we ask (see Studies $1-3)$ :

- $R Q$ 2: Do women and men differ in their beliefs about the causes of gender differences in negotiation?

Finally, we examine the potential consequences of people's beliefs about the causes of gender differences in negotiation (see also Manea et al. 2020). This point is relevant because knowledge about the causes of gender differences is used to mitigate them. That is, diversity initiatives are meant to increase representation in leadership positions and pay equity (Kalev et al. 2006; Leslie 2019). Diversity initiatives comprise different forms, such as training decision-makers to avoid discrimination or enhancing specific skills, such as negotiation, for the target group (Leslie 2019).

Yet, diversity initiatives often are not implemented well and are not necessarily supported by all stakeholders (Berdahl et al. 2018; Nishii et al. 2018). Perhaps 
people only perceive a certain diversity initiative as effective, and are willing to support it, to the extent that it addresses what is perceived as the cause of the particular inequity. That is, people might view an initiative that targets processes concerning women (or men) as effective and be willing to support it only to the extent to which they believe that processes concerning women (or men) underlie gender inequities. This notion is relevant because progress toward gender parity likely is hindered if people do not deem a relevant diversity initiative as effective and support it. Thus, we ask (see Study 3):

- $R Q$ 3: Are people's beliefs about the causes of gender differences in negotiation related to their perceived effectiveness of and willingness to support different diversity initiatives?

We conducted 3 studies to answer our RQs. Studies 1 and 2 examine RQs 1 and 2, whereas Study 3 examines all 3 RQs. We always report our sample sizes, exclusions, measures, and manipulations (Simmons et al. 2012).

\section{Study 1}

\subsection{Method}

\subsubsection{Overview of Design}

Study 1 is a quantitative, exploratory study focusing on RQs 1 and 2. We also designed Study 1 to explore the generalizability of the observed findings: first, negotiation research is typically conducted with students recruited in university contexts (e.g., Hüffmeier et al. 2011; Kennedy and Kray 2015), which may limit its generalizability. Thus, half of our participants were recruited on the campus of a major German university $(n=100)$, whereas another half $(n=100)$ were recruited off campus (e.g., in public places; a minority of the second half were also acquaintances of the experimenter). Second, we recruited 50 men and 50 women on campus, and also 50 women and 50 men off campus. Third, we built two survey versions to address potential order effects. Fourth, we examined the influence of negotiation experience (Mazei et al. 2015). Finally, we asked participants to indicate which gender is more successful at negotiating because people might differ in their beliefs about causes depending on their general perceptions of gender differences.

\subsubsection{Sample}

We aimed to recruit 200 participants, and 200 participants ultimately took part in our study. A sensitivity power analysis (two-tailed, $\alpha \& \beta=0.05$ ) performed with G*Power (Faul et al. 2007) based on a design examining differences between two dependent means revealed that effect sizes as small as $d z=0.26$ can be detected with this sample size. One male participant who gave an answer that suggested he was not taking the study seriously was excluded from all analyses. The average 
age of the included participants was $M=30.36$ years $(S D=12.56$; range: $18-67$; one participant did not indicate his age). The sample consisted of 81 students, 71 working participants, 10 participants indicating other occupational activities, and 37 participants indicating multiple occupational activities. Of the 71 working participants, 11 described their work as realistic, one as investigative, four as artistic, 22 as social, 13 as enterprising, and six as conventional (see Holland 1996); 14 participants indicated multiple characterizations.

\subsubsection{Procedure}

Participants were asked to fill out a paper-pencil survey that can be retrieved here: https://osf.io/ykfs2/?view_only=9136049f14304525808f9cea36b8eed3 (the data are also available as per this link). Participants read that research has observed gender differences in negotiations, yet that their causes are not yet well understood, which is why we asked participants for their assessment.

\subsubsection{First Measure on People's Beliefs about the Causes of Gender Differences}

Participants then indicated on a scale ranging from 1 (do not agree at all; or strongly disagree, in the English version of this measure as used in Study 3) to 7 (strongly agree) their beliefs regarding six processes. The processes are shown in Table 1, along with the orders in which they were presented depending on the survey version. The processes were preceded by the statement: "Gender differences in negotiations emerge because ...".

Three processes, chosen on the basis of their central role in past work (see Table 1), concerned women. Although all 3 processes concerned women, they differed in content and the perspective that is taken (i.e., women's feelings and perceptions as compared to other people's expectations regarding women; see Rudman and Fairchild 2004). Moreover, 3 processes concerned men, which again reflect key notions in extant work (e.g., Kennedy and Kray 2015; Mazei et al. 2021; see Table 1). Altogether, the first measure followed a within-subjects design with one factor and six levels. Within-subjects designs provide rich context information as participants can directly compare different stimuli with each other, and, thus, these designs are "useful in terms of uncovering judgment processes of a single individual" (Aguinis and Bradley 2014, p. 361).

There were 3 missing values in participants' answers to this measure. The pattern of missing values did not differ from missing completely at random, $\chi^{2}(9)=5.01, p=0.833$. The missing values were replaced with the mean response across all six processes $(M=4.15)$. As a sensitivity analysis, we performed a Friedman's ANOVA (see Results section) while excluding cases with missing values. The same effects emerged in this sensitivity analysis. Thus, to avoid losing any data, we report analyses in which missing values were replaced below. 


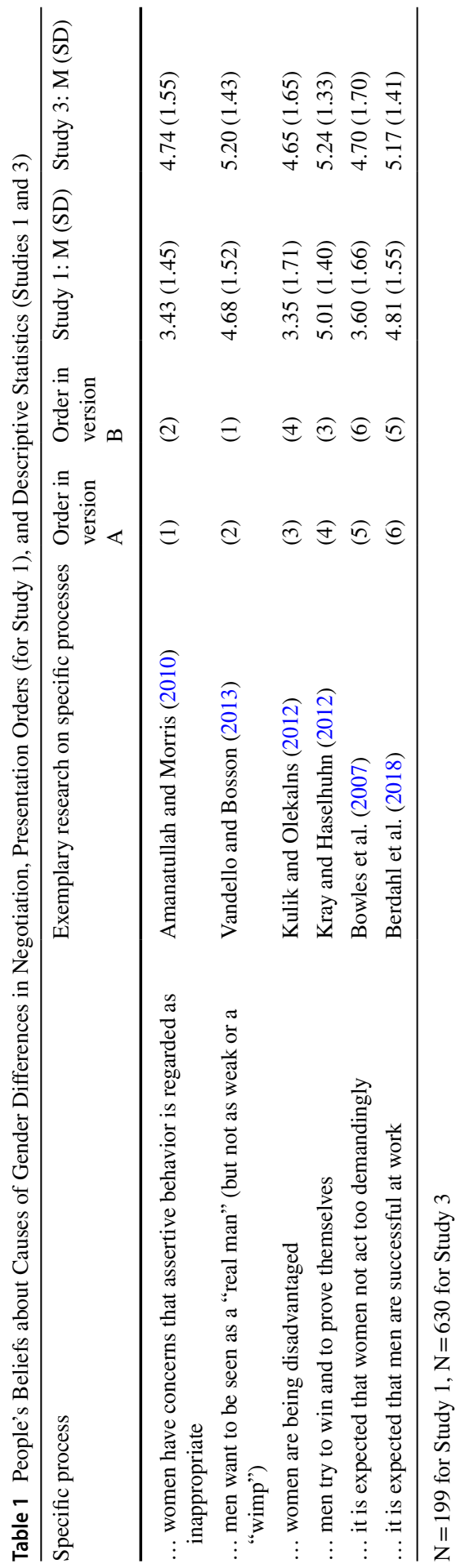




\subsubsection{Second Measure on People's Beliefs about the Causes of Gender Differences}

Participants indicated on a bipolar scale how relevant they believed processes that concern women to be, generally speaking, directly in comparison to processes that concern men for the emergence of gender differences. Participants provided answers on a 7-point scale that was anchored with "Men. It is due to their behavior and the expectations toward them" and with "Women. It is due to their behavior and the expectations toward them," with a middle option of "It is due to both genders equally" (which anchor was provided on the left hand side again depended on the survey version). In the analyses, lower values on this measure indicate stronger beliefs in processes that concern men.

Three participants provided unclear responses to this item (e.g., they marked the scale twice, at two different places). These responses were replaced with the mean response to this item $(M=3.83)$. As a sensitivity analysis, we examined whether a one sample $t$-test (see Results section) yielded different results when these cases were excluded. However, the results were again robust. Thus, we again report analyses in which these responses were replaced.

\subsubsection{Demographics}

Participants indicated their demographics and noted whether German was their first language (respectively, whether they spoke German as well as their first language; $n=195$ indicated that this was the case; the other four participants were also most likely fluent in German as they were students).

\subsubsection{Negotiation Experience}

Participants indicated on a scale ranging from 1 (not at all) to 7 (very) how experienced they were regarding negotiating $(M=3.84, S D=1.55)$. There were two missing values, but the results for negotiation experience did not differ depending on whether missing values were replaced with the mean or whether these cases were excluded.

\subsubsection{Perceived Direction of Gender Difference}

Participants indicated how men and women compared as negotiators. The two response options were "women negotiate worse than men" (as chosen by 140 participants) and "men negotiate worse than women" (as chosen by 45 participants; the order of the response options again depended on the survey version). Fourteen participants did not provide an answer to this item at all or provided an ambiguous answer, but the results for this factor did not differ depending on whether these participants were excluded or not. Thus, again to avoid losing any data, we treated this item as a factor with 3 levels (i.e., women negotiate worse than men vs. men negotiate worse than women vs. missing/ambiguous). Please note that, in the introduction to the study, we did not provide a verbal comparison of women and men, for instance, in the form of "women negotiate worse than men." Doing so might have 
introduced a linguistic framing effect (Bruckmüller et al. 2012; Miller et al. 1991), which could have influenced the results.

\subsection{Results}

\subsubsection{First Measure}

The within-subjects factor, denoted as "process," is key to examine RQ 1, asking how much people believe in processes concerning men versus women. Table 1 depicts descriptive statistics. Our study also included the between-subjects factors of recruitment location, survey version, and participant gender (see RQ 2, asking whether women and men differ in their beliefs). Moreover, we measured people's negotiation experience (a covariate) and their perceptions of the direction of gender differences. Thus, we first conducted a mixed ANCOVA including all of these predictors. These results should be interpreted with caution, however, because assumptions for conducting parametric tests were not met. Given that the assumption of sphericity was not met, we report Huynh-Feldt-corrected statistics. The mixed ANCOVA only revealed a main effect for the process-factor, $F(4.97,874.84)=7.80$, $p<0.001, \eta_{\mathrm{p}}{ }^{2}=0.04$, but no other effects (all $F \mathrm{~s} \leq 2.67$, all $p \mathrm{~s} \geq 0.104$ ).

Hence, we next conducted a Friedman's ANOVA as a robust analysis (Field 2013). The Friedman's ANOVA again revealed significant differences among the six processes, $\chi^{2}(5)=244.22, p<0.001$. Pairwise comparisons with Bonferroni-corrected $p$ values revealed that all 3 processes that concerned women did not differ from each other (all $z \mathrm{~s} \leq \mid 1.06 \mathrm{l}$, all $p \mathrm{~s}=1.00, n s$ ), just like all 3 processes that concerned men did not differ from each other (all $z \mathrm{~s} \leq 12.21 \mathrm{l}$, all $p \mathrm{~s} \geq 0.406$, $n s$ ). However, people endorsed more strongly each process concerning men in comparison to each process concerning women. Table 2 provides inferential statistics and effect sizes. The average effect size was large (Cumming 2014).

Table 2 Inferential Statistics and Effect Sizes (Studies 1 and 3)

\begin{tabular}{|c|c|c|c|c|c|c|c|c|}
\hline \multirow[t]{2}{*}{ Comparison } & & & \multicolumn{3}{|c|}{ Study $1(N=199)$} & \multicolumn{3}{|c|}{ Study $3(N=630)$} \\
\hline & & & $z$ & $p$ & $d$ & $z$ & $p$ & $d$ \\
\hline Women: concerns & vs & Men: "real" man & -7.68 & $<.001$ & 0.85 & -5.50 & $<.001$ & 0.31 \\
\hline Women: concerns & vs & Men: prove themselves & -9.89 & $<.001$ & 1.11 & -5.55 & $<.001$ & 0.35 \\
\hline Women: concerns & vs & Men: work success & -8.63 & $<.001$ & 0.92 & -5.20 & $<.001$ & 0.29 \\
\hline Women: disadvantaged & vs & Men: "real" man & -7.60 & $<.001$ & 0.83 & -6.66 & $<.001$ & 0.36 \\
\hline Women: disadvantaged & vs & Men: prove themselves & -9.81 & $<.001$ & 1.06 & -6.70 & $<.001$ & 0.39 \\
\hline Women: disadvantaged & vs & Men: work success & -8.55 & $<.001$ & 0.90 & -6.35 & $<.001$ & 0.34 \\
\hline Women: not demanding & vs & Men: "real" man & -6.62 & $<.001$ & 0.68 & -5.42 & $<.001$ & 0.32 \\
\hline Women: not demanding & vs & Men: prove themselves & -8.83 & $<.001$ & 0.92 & -5.47 & $<.001$ & 0.35 \\
\hline Women: not demanding & vs & Men: work success & -7.57 & $<.001$ & 0.75 & -5.11 & $<.001$ & 0.30 \\
\hline Average & & & & & 0.89 & & & 0.33 \\
\hline
\end{tabular}

$d$ 's reflect effect sizes for matched groups (Cooper et al. 2009). Positive $d$ 's indicate stronger beliefs in processes that concernmen 


\subsubsection{Second Measure}

To examine RQ 1, we compared the mean response on the bipolar scale to its midpoint (i.e., 4). A non-significant result would indicate the belief that gender differences are due to women and men equally. A Shapiro-Wilk test suggested that the assumption of normality was not met. Thus, we conducted a one-sample $t$-test with bootstrapping (bias corrected and accelerated; 5000 samples). The mean response, $M=3.83(S D=0.96)$, was lower than the midpoint of the scale, $t(198)=-2.48$, bootstrapped $p=0.016,95 \%$ BCa CI $[-0.30,-0.03]$. Although this finding was significant, suggesting that people endorsed processes concerning men, the mean response was just 0.17 points below the midpoint. Thus, the practical relevance of this finding should not be overstated, and a conservative interpretation would be that people tend towards the belief that gender differences are due to processes that concern both women and men.

We next conducted an ANCOVA to explore whether responses to the second measure were influenced by participant gender (see RQ 2), along with the survey version, recruitment location, negotiation experience, and people's answers to the item asking how women and men compare as negotiators. The analysis did not reveal any effects for gender or the other variables (all $F_{\mathrm{s}} \leq 3.58$, all $p \mathrm{~s} \geq 0.060, n s$ ), thereby not suggesting gender differences in beliefs (see RQ 2).

\subsection{Discussion}

Both women and men more strongly endorsed processes underlying gender differences in negotiation that concern men (see RQs 1 and 2). This does not mean, however, that people rejected processes that concern women: As shown in Table 1, people believed in processes that concern women to a moderate degree (see also the results on our second measure on people's beliefs about the causes of gender differences). Hence, altogether, the key finding of Study 1 is that participants endorsed processes that concern both women and men, which is contrary to the tendency in extant research to mainly examine processes concerning women. Study 1 is limited, however, as participants responded to a predetermined set of certain processes.

\section{Study 2}

To address the aforementioned limitation, we conducted Study 2 that utilized an open-ended, qualitative method. We preregistered the expectation that, although some participants would mention processes concerning women as underlying gender differences in negotiation, other participants would mention processes concerning men. In other words, we expected that people would mention processes concerning both women and men. This expectation was based on Study 1 and research by Kray et al. (2001): they asked participants to write an essay about whether and why they think one gender is more successful in negotiation. Participants typically believed 
that men are more successful, and the most common reason was that "men do not want to lose to women" (Kray et al. 2001, p. 958). However, this study included only a rather small and selective sample of 50 MBA students, most of them being men, which may have increased the likelihood of observing an endorsement of processes that concern men. Similarly, participants were asked which gender "has the distributive advantage" (Kray et al. 2001, p. 944), which again might have led participants to mention processes that concern men, as men typically do have the economic "advantage" (e.g., Stuhlmacher and Walters 1999). These limitations highlight the need for additional research.

Our preregistration, study materials, and data for Study 2 can be retrieved here: https://osf.io/3ythj/?view_only=6444338886af4847828185e50bf19f1e; and here https://osf.io/5jgva/?view_only=598cda63ab224a4e9ece7925127d6d31.

\subsection{Method}

\subsubsection{Sample}

We aimed to recruit 100 German participants via an online panel (i.e., Prolific) to take part in a study about "beliefs on the topic of gender and negotiation," for which they received $£ 0.75$ as remuneration. The panel appeared to have invited slightly more participants, as our study was accessed 115 times. Following our preregistration, we excluded 13 participants who accessed the study, but later did not consent to the use of their data.

The average age of the $N=102$ participants was $M=29.58$ years $(S D=10.93$; range: 18-68). The sample consisted of 37 women, 64 men, and one participant who selected "diverse" as their gender (e.g., Eddy 2018). Participants' occupational activities were as follows: 42 college students, 3 high-school students, 43 working participants, and 14 participants indicating other occupational activities. Of the 43 working participants, four described their work as realistic, 13 as investigative, six as artistic, six as social, 10 as enterprising, and four as conventional (Holland 1996).

\subsubsection{Procedure}

Participants were asked: "What do you think: What is the cause, or are the causes, of gender differences in negotiation? In other words, which process, or which processes, underlie gender differences in negotiation?" Participants were asked to describe at least one process using a text box.

\subsubsection{Further Measures}

Participants provided information on their demographics, they noted whether German was their first language (respectively, whether they spoke German as well as their first language; $n=100$ indicated that this was the case), they indicated their degree of negotiation experience $(M=3.31, S D=1.54)$, and their perceptions 
regarding the direction of the gender difference (79 participants chose "women negotiate worse than men," and 23 participants chose "men negotiate worse than women").

\subsubsection{Coding}

One of the authors and a Master's student conducted the coding. To make sure that both coders had the same understanding of our coding scheme, we began by coding an initial set of ten responses and then compared our coding. This initial set was not included when examining interrater reliability. The remaining responses were coded independently by the two coders.

If a response included a process that concerned women, we coded that at least one process concerning women was mentioned $(\kappa=1.00)$. Likewise, if a response included a process that concerned men, we coded that at least one process concerning men was mentioned $(\kappa=0.98)$. If a response could not be clearly categorized, for instance, as a response did not clearly refer to a particular gender but only mentioned "discrimination" or "prejudice," we coded the response as "unclear or mixed" $(\kappa=0.97)$. In our preregistration, we also mentioned that we would code each individual process if more than one process was mentioned. However, during the coding process, it became evident that it was unclear how many processes participants meant to indicate. For instance, it was unclear at times whether participants were elaborating on the consequences of one particular process or already describing another process. This unexpected difficulty is reflected in the related low interrater reliabilities: we used a dummy-coded variable with two levels (i.e., a participant mentioned multiple processes concerning women $[=1]$ or not $[=0]$ ), for which the interrater agreement was estimated at $\kappa=0.61$; for another dummy-variable indicating whether or not multiple processes concerning men were mentioned, $\kappa=0.26$. Thus, to remain conservative in our conclusions, we refrained from analyzing whether participants had mentioned multiple processes and exactly how many processes participants had mentioned.

Finally, we analyzed participants' responses in a bottom-up fashion. The Master's student began by developing and assigning codes for each response. One of the authors then also went through each response and thoroughly examined and refined the themes.

\subsection{Results}

Of the $N=102$ participants, 64 mentioned at least one process that concerned women, and 56 mentioned at least one process that concerned men ( 24 participants provided unclear or mixed responses). Hence, participants mentioned not only processes that concerned women but also processes concerning men. These basic frequencies inform RQ 1 and are generally in line with our preregistered expectation that people would mention processes concerning both women and men.

We next more closely examined how many participants indicated processes that concerned women relative to processes that concerned men by creating a new 
variable with 3 categories, denoted as "categorization of responses": a participant mentioned (a) only one or more processes that concerned women, (b) only one or more processes that concerned men, or (c) processes that concerned both women and men. Following our preregistration, participants who gave unclear responses were excluded from this analysis $(n=24)$. A goodness-of-fit test revealed that categories were not distributed equally, $\chi^{2}(2)=16.00, p<0.001$. Again, generally in line with our expectations (see above), most participants $(n=42)$ mentioned processes that concerned both women and men, although there were slightly more participants $(n=22)$ who mentioned only processes that concerned women compared to participants $(n=14)$ who only mentioned processes that concerned men.

Then, we explored the effects of people's perceived direction of gender differences, negotiation experience, and gender (participants who gave unclear responses were again excluded). In line with Study 1, there were no significant relationships between categorization of responses and people's perception of which gender is more successful at negotiating, $\chi^{2}(2)=2.99, p=0.225$, or their level of negotiation experience, $\chi^{2}(2)=0.03, p=0.988$ (for this analysis, experience was dichotomized, such that values of 1 to 3 were recoded as $0=$ less experience, $n=45$, and values of 4-7 were recoded as $1=$ more experience, $n=33$ ). However, there was a significant relationship between categorization of responses and participant gender, $\chi^{2}(2)=8.94, p=0.011$. Of the 32 women in this analysis, 14 mentioned only processes that concerned women, two mentioned only processes that concerned men, and 16 mentioned processes that concerned both women and men. Of the 46 men in this analysis, eight mentioned only processes that concerned women, 12 mentioned only processes that concerned men, and 26 mentioned processes that concerned both women and men. Thus, although both women and men were most likely to mention processes that concerned both women and men, they were also more likely to mention only processes that concern their own gender compared to processes concerning the other gender. A relationship with participant gender was not observed in Study 1 , yet this finding informs RQ 2 and supports the notion presented in the General Introduction that people who are not subject to a process may not easily notice its presence.

Finally, we examined participants' responses in a bottom-up fashion. The results are presented in Table 3. Given our focus on processes that specifically concern women or men, the table does not include themes that did not clearly refer to a particular gender (likewise, the table does not include themes by participants who only provided unclear responses). The first category of themes revolved around attributes and behaviors of women and men. For example, women were often described as cooperative or emotional (e.g., Eagly et al. 2020). Thus, themes emerged-such as feminine attributes or women's fear of backlash - that are consistent with extant research. Likewise, themes regarding men emerged that mirror past research. For example, men were described as assertive or dominant (e.g., Rudman et al. 2012). Similarly, participants mentioned men's toughness (Berke et al. 2017; Fowler and Geers 2017), that they aim to win (Kray and Haselhuhn 2012), or that they ought to be successful (Berdahl et al. 2018; Williams et al. 2016).

Study 2 also yielded themes that have received relatively little attention, such as physical (see also Haselhuhn et al. 2014) or evolutionary aspects. For 
Table 3 Themes (Study 2)

Themes related to women

Themes related to men

$(k=52)$

$(k=30)$

\section{Attributes and behaviors}

cooperativeness (socialized or gender role; 8 ); emotional (6); empathy (6); gender roles (6); restraint (socialized; 6); backlash (4); fear of backlash (4); lack of confidence (3); language (3); accommodating (2); compromising (2); lack of assertiveness (2); not being taken seriously (2); self-fulfilling prophecy (2); underestimation of own skills (2); act "manly"; agreeableness; caring (socialized); demeanor; emotional intelligence; feminine charm; guilt; humility; intimidated; motherliness; multitasking; lack of aggressiveness (socialized); not thought to be ambitious; passive; politeness (socialized); prejudice; proscribed to self-promote; scrutinized; seen as less dominant; seen as weaker sex; sensitive; socialization; softness; submissiveness

$(k=39)$

Physical characteristics and evolutionary aspects

pregnancy/motherhood (5); evolution/biology (2); appearance; attractiveness; physical weakness; prosocial (evolutionary)

$(k=6)$

Structural issues

disadvantaged (4); caregiving; low chances of being promoted; lower social status; part-time work; represented in leadership positions; underpaid

$(k=7)$ assertiveness (socialized, gender role, or evolutionary/biological; 8); dominance (socialized, gender role, or evolutionary/biological; 8); (over) confidence (6); aggressiveness (socialized; 5); rational (4); competitiveness (socialized or gender role; 3); gender roles (3); persistence (3); toughness (socialized; 2); prejudiced (2); selfishness (2); aim to win; being taken seriously; chivalry; comfortable to sentence someone; demanding; downplaying incidents; emotional stability; intimidated; ought to be successful; power; resilience; risk-taking

$(k=23)$

physical strength (3); attracting mates; evolution/ biology; intrasexual competition

$(k=4)$

breadwinner (2); higher social status; men as leaders

$(k=3)$

Some participants linked, for instance, an attribute to a more "distal" cause (e.g., socialization), so that we added this note in parentheses. For themes that emerged multiple times, the respective frequencies are also given in parentheses (see Kray et al. 2001). $k$ refers to the number of themes but not participants (participants could mention more than one theme)

example, participants described that motherhood (or being pregnant) can yield problems for women (Bear and Glick 2017; Correll et al. 2007). Similarly, participants mentioned men's physical strength or the issue of intrasexual competition among men (Lee et al. 2017). Another category of themes involved more structural issues. For example, participants mentioned caregiving duties or parttime work among women (Artz et al. 2018; Mazei and Hüffmeier 2021), as well as men's breadwinner status (see also Bowles and McGinn 2008; Livingston 2014). 


\subsection{Discussion}

Women and men typically mentioned processes underlying gender differences in negotiation concerning both women and men (RQ 1). Moreover, women and men slightly differed in their beliefs about the causes of gender differences in negotiation (RQ 2). Finally, many processes were mentioned that are already well known in the literature (recall that our first measure on people's beliefs about the causes of gender differences in negotiation in Study 1 was also based on extant research). Yet, additional themes emerged that have yet to be investigated in greater depth (e.g., the roles of motherhood or physical strength). Altogether, the key finding of Study 2 is again that participants endorsed not only processes that concern women, which have been mainly explored in past research, but also processes concerning men.

\section{Study 3}

Despite their strengths, Studies 1 and 2 did not address the practical consequences of people's beliefs (e.g., Manea et al. 2020; Ross et al. 2010). Thus, we conducted Study 3-a quantitative, confirmatory study - to examine all 3 RQs. Based on our results from Study 1, we hypothesized that people would believe more strongly in processes that concern men relative to processes that concern women (Hypothesis 1). In line with their beliefs about causes, we hypothesized that people would believe that diversity initiatives that are based on processes that concern men are more effective (Hypothesis 2a), and that they would be willing to support them (Hypothesis $2 b$ ), relative to diversity initiatives based on processes that concern women. Furthermore, we hypothesized that the more people believe in processes that concern men as underlying gender differences in negotiation, the more they will perceive diversity initiatives based on processes that concern men as effective (Hypothesis 3a) and the more they will support them (Hypothesis 3b). Likewise, the more people believe in processes that concern women as underlying gender differences in negotiation, the more they will perceive diversity initiatives based on processes that concern women as effective (Hypothesis 4a) and the more they will support them (Hypothesis 4b).

Our preregistration, study materials, and data for Study 3 can be retrieved here: https://osf.io/pqzhx/?view_only=0b6730cf51c343b1ba39c8ce4b0a3cdb; and here: https://osf.io/kp456/?view_only=3e66a08cc1714073a71c7a8575ccd30a.

\subsection{Method}

\subsubsection{Sample}

Leslie et al. (2020) examined (among other factors) the relationships among different types of "beliefs regarding the importance of demographic differences and how to navigate them" (p. 453) and support for different diversity policies. They observed (uncorrected) correlations between $r=-0.20$ and $r=0.45$. As we examine a novel 
domain, we use the more conservative effect size of $r=|.20|$ for our a priori power analyses that we performed with $\mathrm{G}^{*}$ Power (Faul et al. 2007). The analysis yielded a needed sample size of $N=319$ (two-tailed, $\alpha \& \beta=0.05$ ). A sensitivity power analysis (two-tailed, $\alpha \& \beta=0.05$ ) based on a design examining differences between two dependent means — as is relevant for Hypotheses 1, 2a, and 2b-revealed that effect sizes as small as $d z=0.20$ can be detected with such a sample size (Study 1 revealed larger effect sizes). Finally, as we are interested in the generalizability of our results, we conducted Study 3 with participants from Germany and the United States.

Thus, we aimed to recruit 319 German participants as well as 319 U.S. participants via an online panel (i.e., Prolific) to take part in a study about "beliefs about gender, negotiation, and interventions," for which they received $£ 1.50$ as remuneration. Participants who took part in Study 2 were not allowed to take part in Study 3. The panel again appeared to have invited slightly more participants (which we included as an expectation in our preregistration, following our experiences with Study 2). Following our preregistration, we excluded 31 participants who did not give their consent after accessing the study, nine additional participants who did not pass an attention check (see below), and one additional participant who appeared to take part twice (this criterion was not preregistered, yet we deem it a straightforward decision to exclude this participant).

The average age of the final $N=630$ participants, composed of 313 participants from the U.S. and 317 participants from Germany, was $M=31.69$ years $(S D=10.50$; range: 18-75). The final sample consisted of 283 women, 338 men, and nine participants who selected "diverse" as their gender. Participants' occupational activities were as follows: 281 participants were working full time, 106 were working parttime, 154 were full-time students, and 89 indicated "other" activities. Of the 387 working participants, 44 described their work as realistic, 74 as investigative, 34 as artistic, 79 as social, 78 as enterprising, and 78 as conventional (Holland 1996).

\subsubsection{Procedure}

Participants responded to the first measure on people's beliefs about the causes of gender differences in negotiation from Study 1 (the 6 processes were presented in randomized order). Afterwards, they were shown 7 different diversity initiatives (Table 4) that were all presented with the same goal: to reduce gender differences in negotiation. Participants were asked to indicate on a scale ranging from 1 (not effective at all) to 7 (very effective) how they would evaluate, all things considered, their effectiveness (adapted from Rynes and Rosen 1995). The diversity initiatives were again grounded in extant work (e.g., Amanatullah and Morris 2010; Bowles et al. 2007; Leslie 2019). For example, research has examined negotiation strategies for women (e.g., Bear and Babcock 2017; Bowles and Babcock 2013) that can be taught in trainings. Similarly, research has examined whether men with atypical characteristics can avoid losses in their social status if alternative "proof" of their masculinity is available (Brescoll et al 2012; see also Fowler and Geers 2017), which can again be covered in trainings for men (see also Berdahl et al. 2018 on "masculine contest cultures"). Generally, diversity initiatives typically concern trainings aimed at a target group or at informing participants about prejudice and discrimination (see the 


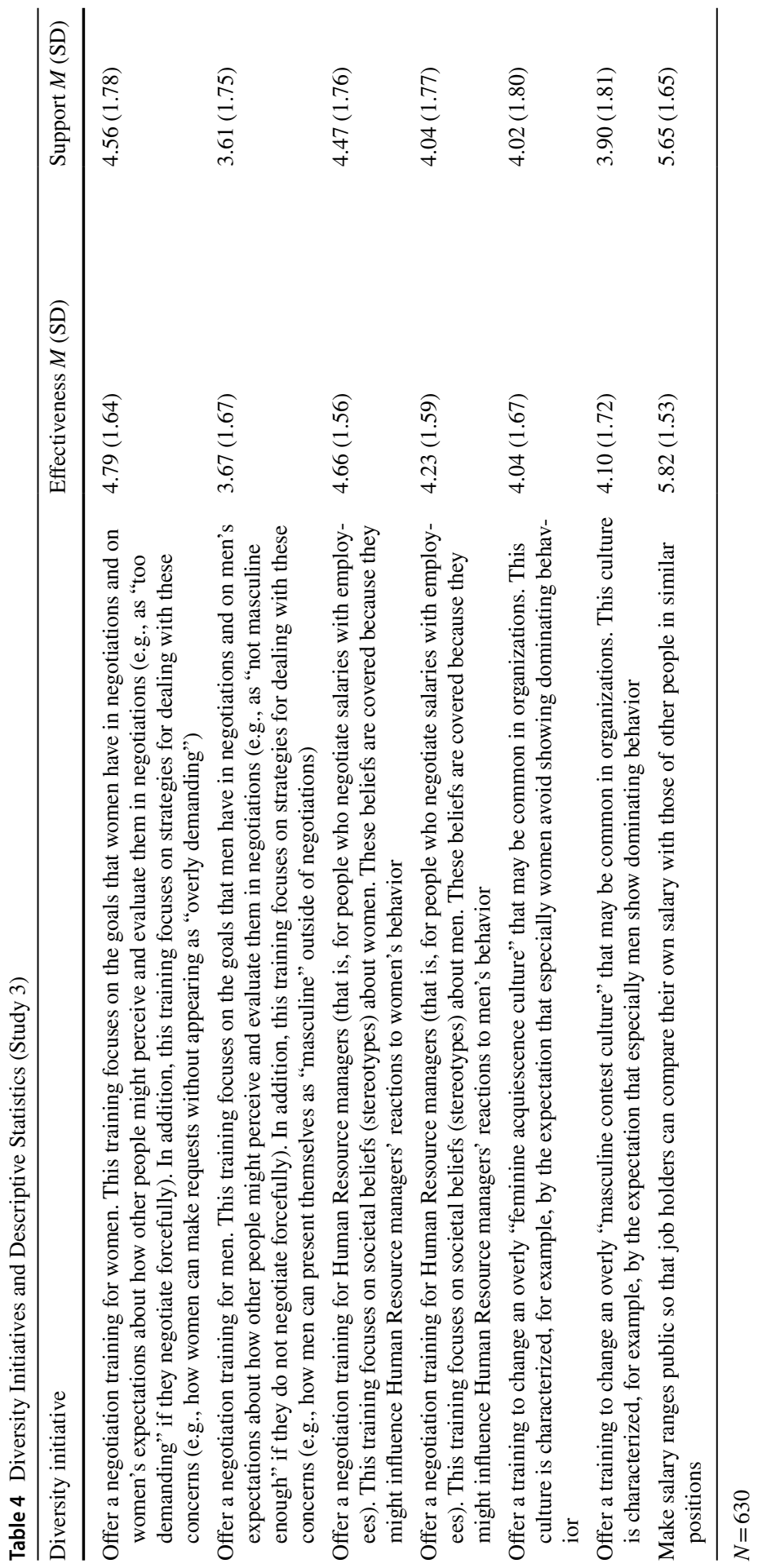


initiatives for HR managers in Table 4; Leslie 2019). For exploratory reasons, we included another diversity initiative that did not refer to a particular gender-making salary ranges public_-given the known relevance of pay transparency (e.g., Bowles et al. 2005; Recalde and Vesterlund 2020). The diversity initiatives were presented in randomized order, except for the one on salary ranges, which was always presented last.

Afterwards, participants were asked to imagine that the interventions could be adopted in an organization that they work for, and to indicate how strongly they would support each of the seven diversity initiatives, for example, by personally investing time and energy for their development, announcement, and implementation, using a scale that ranged from 1 (not at all) to 7 (very strongly).

\subsubsection{Further Measures}

Participants provided information on their demographics. They also noted whether German (for German participants) or English (for U.S. participants) was their first language (respectively, whether they spoke German, or English, as well as their first language; $n=625$ indicated that this was the case), they indicated their degree of negotiation experience $(M=3.45, S D=1.59)$, they responded to an attention check asking them to simply choose a certain response option, and they indicated their perceptions regarding the direction of the gender difference $(n=479$ participants chose "women negotiate worse than men, and $n=151$ participants chose "men negotiate worse than women"). Findings related to people's perceptions regarding the direction of the gender difference should be interpreted with caution because multiple participants stated, for instance, that they would have liked to have a third response option indicating that women and men negotiate equally well. Finally, participants were allowed to leave comments about the study.

\subsection{Results}

\subsubsection{Hypothesis 1}

Following our preregistration, we conducted a Friedman's ANOVA and pairwise comparisons as follow-up tests, as assumptions for conducting parametric tests were not met. We also preregistered this type of analysis because Study 1 that also used this measure only suggested a main effect for the process-factor. The Friedman's ANOVA revealed significant differences among the six processes, $\chi^{2}(5)=126.42$, $p<0.001$. Pairwise comparisons with Bonferroni-corrected $p$ values revealed that all 3 processes that concerned women did not differ from each other (all $z \mathrm{~s} \leq 11.24 \mathrm{l}$, all $p \mathrm{~s}=1.00, n s)$, just like all 3 processes that concerned men did not differ from each other (all $z \mathrm{~s} \leq 10.35 \mathrm{l}$, all $\mathrm{ps}=1.00, n s$ ). However, replicating Study 1 , and in line with Hypothesis 1, all 3 processes that concerned women significantly differed from all 3 processes that concerned men. Across all participants, people more strongly 
endorsed processes concerning men (Table 1). Table 2 provides inferential statistics and effect sizes. The average effect size was small (Cumming 2014).

Next, we conducted a mixed ANCOVA to explore the potential influences of people's (a) gender, (b) degree of negotiation experience (a covariate), (c) perception of the direction of gender differences, and (d) cultural background (Germany vs. U.S.). Given that Study 1 only suggested a main effect for the process-factor, it is an open question whether these aspects influence our findings. Thus, in our preregistration, we simply raised an exploratory question asking about the generalizability of our findings. This analysis again needs to be interpreted with caution, as assumptions for conducting parametric tests were not met (we also again report Huynh-Feldt-corrected statistics). Finally, we excluded participants who selected "diverse" as their gender for all following analyses in this section. This was done to prevent any undue overgeneralizations about this group based on the small currently available sample $(n=9)$.

The mixed ANCOVA revealed main effects for participant gender, $F(1$, $612)=17.26, p<0.001, \eta_{\mathrm{p}}{ }^{2}=0.03$, cultural background, $F(1,612)=9.10, p=0.003$, $\eta_{\mathrm{p}}{ }^{2}=0.02$, and negotiation experience (included as a covariate; see Study 1), $F(1$, $612)=5.41, p=0.020, \eta_{\mathrm{p}}{ }^{2}=0.01$. Unlike Study 1 and the Friedman's ANOVA, there was no main effect for the process-factor, $F(4.15,2540.66)=1.60, p=0.170$, $\eta_{\mathrm{p}}{ }^{2}=0.00$, but interactions between the process-factor and (a) participant gender, $F(4.15,2540.66)=4.84, p=0.001, \eta_{\mathrm{p}}{ }^{2}=0.01$, (b) cultural background, $F(4.15$, $2540.66)=4.86, p=0.001, \eta_{\mathrm{p}}{ }^{2}=0.01$, (c) the perception of the direction of gender differences, $F(4.15,2540.66)=5.29, p<0.001, \eta_{\mathrm{p}}{ }^{2}=0.01$, and (d) experience, $F(4.15,2540.66)=3.16, p=0.012, \eta_{\mathrm{p}}{ }^{2}=0.01$ (there was another interaction between participant gender and the perception of the direction of gender differences, $F[1$, $612]=5.68, p=0.017, \eta_{\mathrm{p}}{ }^{2}=0.01$ ). Such interactions were not observed in Study 1 , potentially due to less statistical power. No other effects were significant (all $F \mathrm{~s} \leq 2.87$, all $p \mathrm{~s} \geq 0.054)$.

To visualize the interaction between the process-factor and participant gender (see RQ 2), Fig. 1 ( $N=621$; error bars indicate 95\% CIs) shows estimated marginal means following from the mixed ANCOVA (the additional interactions involving the process-factor can be found in the Online Supplement). Friedman's ANOVAs, conducted separately for the different subgroups, are given underneath each figure (also those in the Online Supplement). Men appeared to endorse processes concerning women to a relatively low extent (see the left hand side of Fig. 1), whereas there was largely a consensus between men and women with respect to their beliefs regarding the importance of processes concerning men (see the right hand side of Fig. 1). Altogether, processes concerning men were endorsed at least as strongly as processes concerning women, if not more so, thereby supporting Hypothesis 1.

\subsubsection{Hypotheses $2 \mathrm{a}$ and $2 \mathrm{~b}$}

Following our preregistration, we tested Hypotheses $2 \mathrm{a}$ and $2 \mathrm{~b}$ again by conducting Friedman's ANOVAs. There were significant differences among the seven diversity initiatives regarding their perceived effectiveness, $\chi^{2}(6)=748.20, p<0.001$, and also regarding people's willingness to support them, $\chi^{2}(6)=667.99, p<0.001$. However, as 


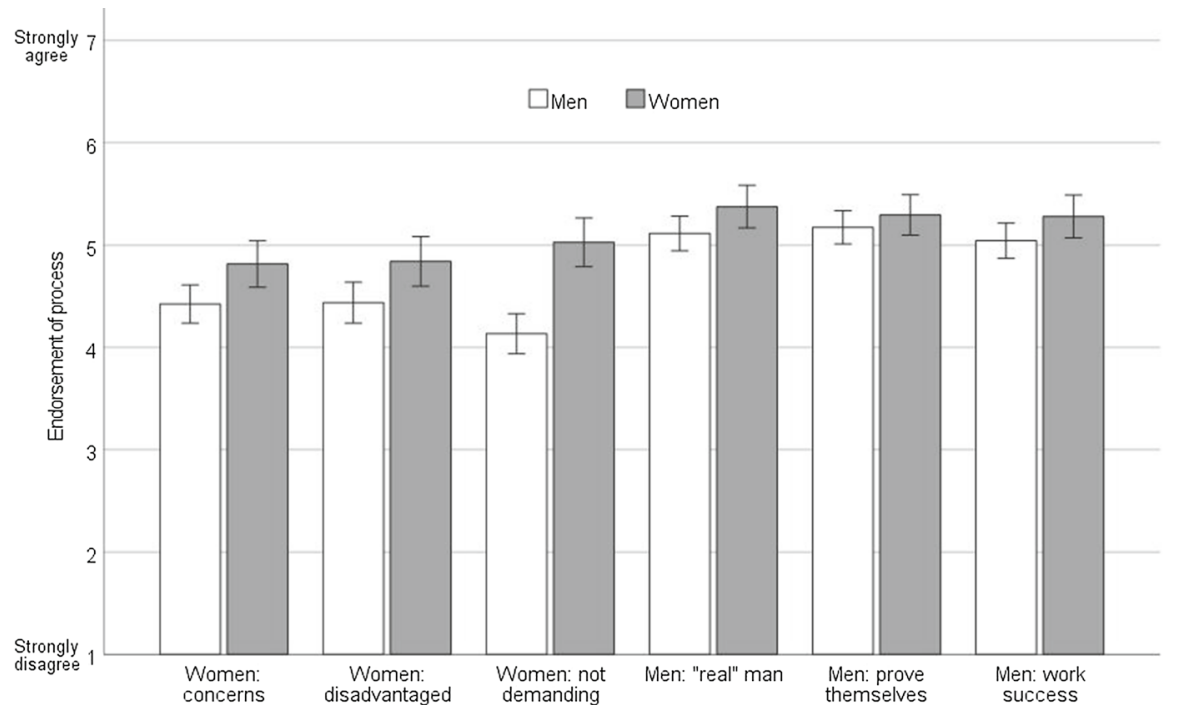

Fig. 1 Beliefs about the Causes of Gender Differences by Participant Gender (Study 3). Note: There were significant differences among the six processes for female participants $(n=283), \chi^{2}(5)=27.84, p<0.001$, and for male participants $(n=338), \chi^{2}(5)=167.93, p<0.001$

shown in Table 4, people typically perceived diversity initiatives focusing on men as less effective, and they were less willing to support them, than the corresponding diversity initiatives focusing on women (see, for example, the lower means for the negotiation training for men as compared to the negotiation training for women). Thus, as Hypotheses $2 \mathrm{a}$ and $2 \mathrm{~b}$ clearly were not supported, we do not report further exploratory analyses for the sake of parsimony.

\subsubsection{Hypotheses 3a, 3b, 4a, and 4b}

As preregistered, we examined the correlations between people's beliefs regarding each of the causes of gender differences in negotiation on the one hand and people's perceptions regarding the effectiveness of the diversity initiatives, as well as their willingness to support them, on the other hand. As is shown in Table 5, the more people believed in causes that concerned men, the more they perceived diversity initiatives focusing on men as effective. They also expressed greater willingness to support these initiatives. Likewise, the more people believed in causes that concerned women, the more they perceived diversity initiatives focusing on women as effective. They also expressed greater willingness to support these initiatives. Thus, Hypotheses 3a, 3b, 4a, and 4b were fully supported. 


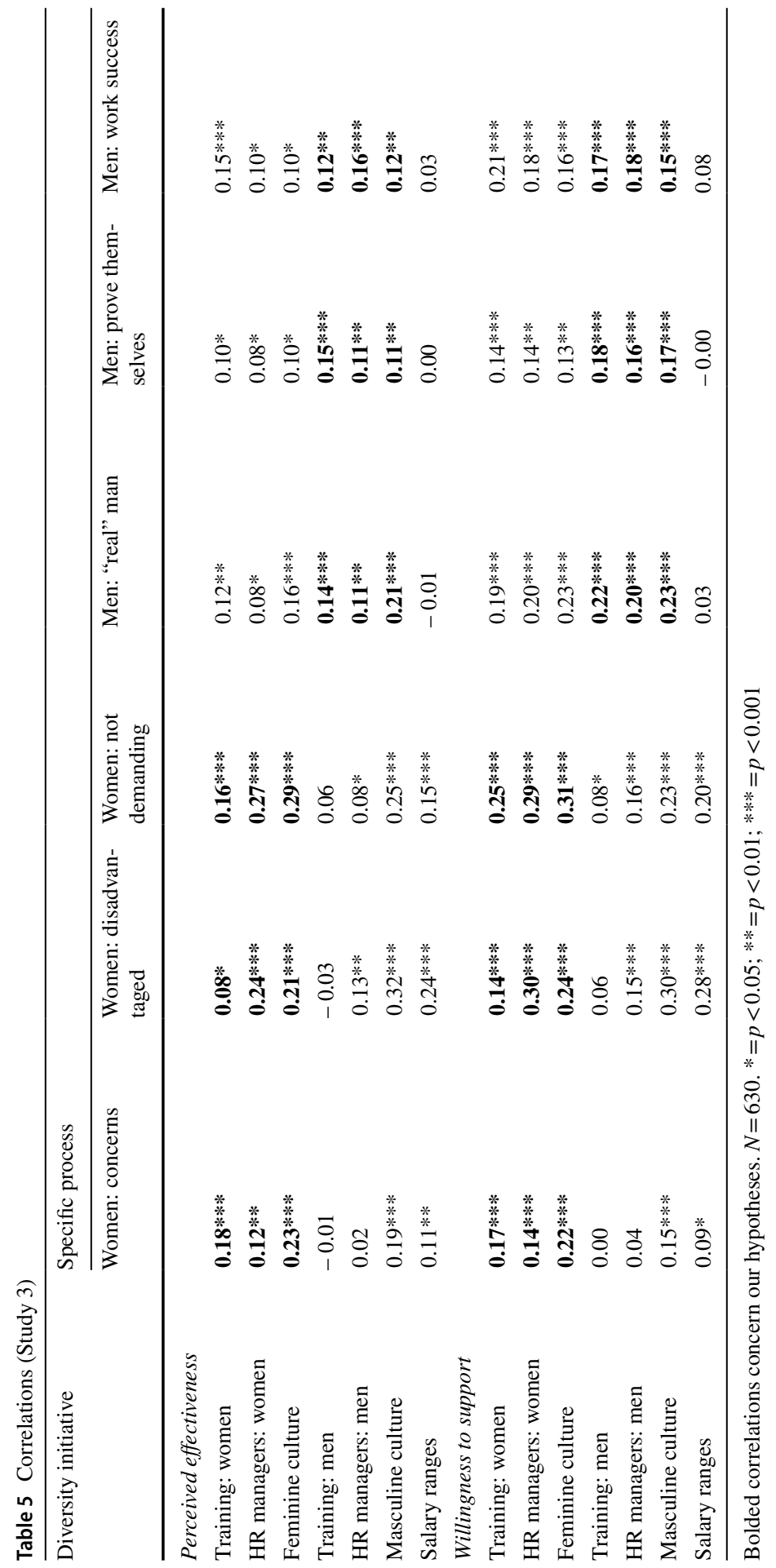




\subsection{Discussion}

In line with Studies 1 and 2, a key finding of Study 3 is that people endorsed not only processes that concern women, but also processes that concern men (in some cases, processes concerning men were endorsed even more). This finding again suggests the potential relevance of processes concerning men, which played a smaller role in past research in comparison to processes concerning women. However, counter to our related hypotheses, people neither perceived diversity initiatives focusing on men as more effective, nor were they more willing to support them, in comparison to diversity initiatives focusing on women. This could be due to the fact that diversity initiatives that focus on women are more common in the workplace. For instance, diversity trainings often focus on a target group (e.g., women; Leslie 2019). Nevertheless, Study 3 revealed that people's beliefs about the causes of gender differences in negotiations were related to people's perceptions of the effectiveness of different diversity initiatives and their willingness to support them.

\section{General Discussion}

\subsection{Implications for Theory and Research}

Across 3 studies, our key insight is that people endorsed processes underlying gender differences in negotiation that concern both women and men, whereas past research has mostly explored processes that concern women. For instance, in Study 2 , people most frequently mentioned processes that concern both women and men (see also Kray et al. 2001). In Studies 1 and 3, at least some people even more strongly endorsed processes that concern men. Our key insight suggests the potential importance of processes concerning men for the emergence of gender differences in negotiation (e.g., Miller 2013; Lee et al. 2017). Hence, delving deeper into processes underlying gender differences in negotiation that concern men is an important avenue for negotiation research.

Our research has important theoretical implications. Men negotiate assertively (Netchaeva et al. 2015) or even unethically as they are "acutely motivated to win" (Kray and Haselhuhn 2012, p. 1124)—notions that Mazei et al. (2021) integrated in their model. Notably, we observed that people's belief system was in line with these notions. For instance, people clearly endorsed processes such as "men try to win" (Kray and Haselhuhn 2012) or that they "want to be seen as 'real' men" (see Table 1; Vandello et al. 2008). As people's beliefs are informed by their everyday observations (Koenig and Eagly 2014), our research supports extant work on masculinity and negotiation. Furthermore, although Hypotheses $2 \mathrm{a}$ and $2 \mathrm{~b}$ were not supported, people's beliefs were related to perceptions of the effectiveness of different diversity initiatives, as well as people's willingness to support them. This is a noteworthy insight because it is known that diversity initiatives often are not implemented well (e.g., Nishii et al. 2018), which hampers progress toward gender equity (see also Berdahl et al. 2018). 
An interesting question that arises from our findings is why people's beliefs do not mirror the past focus on gender in negotiation research. Given that women tend to be disadvantaged in negotiations, it is logical that researchers have focused on what processes hinder women from negotiating successfully. However, as many people perceive manhood as being a "precarious" status (e.g., Bosson et al. 2021; Gilmore 1990), people likely have rich experiences with men aiming to underscore their manhood, also in negotiations (Kray and Haselhuhn 2012; Mazei et al. 2021). Hence, future research could examine in greater depth the pressure that men may experience to negotiate successfully. Men perceive their negotiation performance as affecting their manhood status (Kennedy and Kray 2015; Kray and Haselhuhn 2012). Being unsuccessful in negotiations, then, could create a "double burden" for men, such that they incur not only tangible losses (e.g., a lower than aspired salary) but also losses in their manhood status (e.g., Mazei et al. 2021; Miller 2013).

We also explored whether women and men differ in their beliefs about the causes of gender differences in negotiation (RQ 2). Studies 2 and 3 point to slight differences between the genders. Specifically, in Study 2, women and men were more likely to mention only processes that concern their own gender compared to processes concerning the other gender (see also Swim et al. 2001; Weaver et al. 2010). Similarly, in Study 3, men as compared to women appeared to endorse processes concerning women slightly less. Altogether, our findings support the notion that people may be especially aware of processes that concern their own gender (Swim et al. 2001; Weaver et al. 2010; but see also Bosson et al. 2021).

Our work may also be relevant for research on the phenomenon termed the "effect to be explained" (Miller et al. 1991), which notes that people tend to highlight the group that appears atypical or lower in social status in their explanations of group differences (e.g., Bruckmüller et al. 2012). Following this phenomenon, it is surprising that people did not endorse processes that concern women to a greater extent. Thus, an interesting avenue for future research is to examine in greater depth the potentially manifold roots of people's beliefs. Finally, recall that Study 2 revealed processes that have yet received only scant attention in research on gender and negotiation, including evolutionary and structural factors, which future work could also investigate in greater depth.

\subsection{Implications for Practice}

Women typically earn less than men (Blau and Kahn 2017) and hold fewer top leadership positions (Eagly and Carli 2007) -inequities that research on gender and negotiation aims to address (e.g., Kennedy and Kray 2015; Kulik and Olekalns 2012). Our research highlights that gender differences in negotiation may have multiple causes that relate to both women and men (see also Kennedy and Kray 2015; Kray et al. 2001). Thus, for the successful reduction of gender inequities, it would be helpful to examine and counteract each of these causes (e.g., in the form of diversity initiatives). However, diversity initiatives do not always achieve their goals (Nishii et al. 2018). Our results also speak to this issue: the more people believed in 
a certain cause of gender differences in negotiation, the more willing they were to support certain diversity initiatives. Thus, people's beliefs about the causes of gender differences in negotiation, especially among those responsible for the implementation of diversity initiatives (e.g., Leslie 2019), should be taken into account.

\subsection{Limitations and Routes for Future Research}

In Studies 1 and 3, we measured different constructs with single items. Although this procedure can reduce fatigue among participants, especially when several processes and diversity initiatives have to be assessed, and although our findings appeared to be robust, future research could develop scales to measure these constructs. Moreover, future research is needed to examine the consequences of people's beliefs in longitudinal designs as well as additional diversity initiatives (see also Manea et al. 2020; Meussen et al. 2020). Finally, although Study 3 included participants from Germany and the United States, future research is needed to examine more broadly the potential influence of people's culture (Shan et al. 2016; 2019).

\section{Conclusion}

If people read a typical contemporary article on gender differences in negotiation, they are likely to learn that processes relevant to women are the key to explaining gender differences. Although these processes certainly play a crucial role, our research suggests a more nuanced story: processes that concern men and masculinity (e.g., Kray and Haselhuhn 2012; Netchaeva et al. 2015) are likely to play an important role as well. We hope that our results stimulate future research to shed light on the full range of processes underlying gender differences in negotiation.

Supplementary Information The online version contains supplementary material available at https://doi. org/10.1007/s10726-021-09757-8.

Acknowledgements We thank Sina Brunzel, Christina Datsi, and Laura Offenberg for their help in conducting this research.

Funding Open Access funding enabled and organized by Projekt DEAL. This research was supported by a grant from the Dispute Resolution Research Center at the Kellogg School of Management, Northwestern University, to Julia B. Bear and Jens Mazei.

Availability of Data and Material Our study materials are available online as per the anonymized links that are provided in the manuscript. Our data will also be made available after the publication of this research.

Code Availability Not applicable: our research does not involve the development of software or custom code.

\section{Declarations}

Conflicts of interest We declare that we do not have any conflicts of interests or competing interests that might be interpreted as influencing this research. 
Research Involving Human Participants and/or Animals This research has been conducted in a manner consistent with APA's ethical principles in the conduct of research with human participants. In Germany, where we conducted this research, it is uncommon and not mandatory to seek IRB-approval for each and every study, unlike in the United States. Our study involved only minimal risk given that participants simply filled out a survey. Our research also did not involve any deception, and we always sought informed consent. Thus, we only analyzed data from participants who were clearly willing to participate.

Informed Consent We always sought informed consent.

Open Access This article is licensed under a Creative Commons Attribution 4.0 International License, which permits use, sharing, adaptation, distribution and reproduction in any medium or format, as long as you give appropriate credit to the original author(s) and the source, provide a link to the Creative Commons licence, and indicate if changes were made. The images or other third party material in this article are included in the article's Creative Commons licence, unless indicated otherwise in a credit line to the material. If material is not included in the article's Creative Commons licence and your intended use is not permitted by statutory regulation or exceeds the permitted use, you will need to obtain permission directly from the copyright holder. To view a copy of this licence, visit http://creativecommons.org/licen ses/by/4.0/.

\section{References}

Aguinis H, Bradley KJ (2014) Best practice recommendations for designing and implementing experimental vignette methodology studies. Organ Res Methods 17:351-371. https://doi.org/10.1177/ 1094428114547952

Amanatullah ET, Morris MW (2010) Negotiating gender roles: gender differences in assertive negotiating are mediated by women's fear of backlash and attenuated when negotiating on behalf of others. J Pers Soc Psychol 98:256-267. https://doi.org/10.1037/a0017094

Amanatullah ET, Tinsley CH (2013) Punishing female negotiators for asserting too much...or not enough: Exploring why advocacy moderates backlash against assertive female negotiators. Organ Behav Hum Decis Process 120:110-122. https://doi.org/10.1016/j.obhdp.2012.03.006

Artz B, Goodall AH, Oswald AJ (2018) Do women ask? Ind Relat 57:611-636. https://doi.org/10.1111/ irel.12214

Auletta K (2014) Why Jill Abramson was fired. www.newyorker.com/business/currency/why-jill-abram son-was-fired. Accessed 21 October 2019

Bear JB, Babcock L (2017) Negotiating femininity: gender-relevant primes improve women's economic performance in gender role incongruent negotiations. Psychol Women Q 41:163-174. https://doi. org/10.1177/0361684316679652

Bear JB, Glick P (2017) Breadwinner bonus and caregiver penalty in workplace rewards for men and women. Soc Psychol Person Sci 8:780-788. https://doi.org/10.1177/1948550616683016

Berdahl JL, Cooper M, Glick P, Livingston RW, Williams JC (2018) Work as a masculinity contest. J Soc Issues 74:422-448. https://doi.org/10.1111/josi.12289

Berke DS, Reidy DE, Miller JD, Zeichner A (2017) Take it like a man: gender-threatened men's experience of gender role discrepancy, emotion activation, and pain tolerance. Psychol Men Masc 18:6269. https://doi.org/10.1037/men0000036

Blau FD, Kahn LM (2017) The gender wage gap: extent, trends, and explanations. J Econ Lit 55:789865. https://doi.org/10.1257/jel.20160995

Bosson JK, Vandello JA (2011) Precarious manhood and its links to action and aggression. Curr Dir Psychol Sci 20:82-86. https://doi.org/10.1177/0963721411402669

Bosson JK, Taylor JN, Prewitt-Freilino JL (2006) Gender role violations and identity misclassification: The roles of audience and actor variables. Sex Roles 55:13-24. https://doi.org/10.1007/ s11199-006-9056-5

Bosson JK, Vandello JA, Burnaford RM, Weaver JR, Wasti SA (2009) Precarious manhood and displays of physical aggression. Pers Soc Psychol Bull 35:623-634. https://doi.org/10.1177/0146167208 331161 
Bosson JK, Jurek P, Vandello JA, Kosakowska-Berezecka N, Olech M, Besta T et al (2021) Psychometric properties and correlates of precarious manhood beliefs in 62 nations. J Cross-Cul Psychol 52:231258. https://doi.org/10.1177/0022022121997997

Bowles HR, Babcock L (2013) How can women escape the compensation negotiation dilemma? Relational accounts are one answer. Psychol Women Q 37:80-96. https://doi.org/10.1177/0361684312 455524

Bowles HR, Kray LJ (2013) Negotiation is a man's game: ultimate truth or enduring myth? In Gender and work: challenging conventional wisdom. Harvard Business School Press, Cambridge

Bowles HR, McGinn KL (2008) Gender in job negotiations: a two-level game. Negot J 24:393-410. https://doi.org/10.1111/j.1571-9979.2008.00194.x

Bowles HR, Babcock L, McGinn KL (2005) Constraints and triggers: situational mechanics of gender in negotiation. J Pers Soc Psychol 89:951-965. https://doi.org/10.1037/0022-3514.89.6.951

Bowles HR, Babcock L, Lai L (2007) Social incentives for gender differences in the propensity to initiate negotiations: sometimes it does hurt to ask. Organ Behav Hum Decis Process 103:84-103. https:// doi.org/10.1016/j.obhdp.2006.09.001

Brescoll VL, Uhlmann EL, Moss-Racusin C, Sarnell L (2012) Masculinity, status, and subordination: why working for a gender stereotype violator causes men to lose status. J Exp Soc Psychol 48:354357. https://doi.org/10.1016/j.jesp.2011.06.005

Bruckmüller S, Hegarty P, Abele AE (2012) Framing gender differences: linguistic normativity affects perceptions of power and gender stereotypes. Eur J Soc Psychol 42:210-218. https://doi.org/10. 1002/ejsp. 858

Calhoun P, Smith WP (1999) Integrative bargaining: does gender make a difference? Int J Confl Manag 10:203-224. https://doi.org/10.1108/eb022824

Cantrell RS, Butler JJ (1997) Male negotiators: chivalry or machismo or both? Psychol Rep 80:13151323. https://doi.org/10.2466/pr0.1997.80.3c.1315

Cooper H, Hedges LV, Valentine JC (2009) The handbook of research synthesis and meta-analysis. Russell Sage Foundation, New York

Correll SJ, Benard S, Paik I (2007) Getting a job: is there a motherhood penalty? Am J Sociol 112:12971338. https://doi.org/10.1086/511799

Croft A, Schmader T, Block K (2015) An underexamined inequality: cultural and psychological barriers to men's engagement with communal roles. Pers Soc Psychol Rev 19:343-370. https://doi.org/10. $1177 / 1088868314564789$

Cumming G (2014) The new statistics: why and how. Psychol Sci 25:7-29. https://doi.org/10.1177/09567 97613504966

Eagly AH (1987) Sex differences in social behavior: a social-role interpretation. Lawrence Erlbaum Associates Inc, Hillsdale

Eagly AH, Carli LL (2007) Through the labyrinth: the truth about how women become leaders. Harvard Business School Press, Boston

Eagly AH, Karau SJ (2002) Role congruity theory of prejudice toward female leaders. Psychol Rev 109:573-598. https://doi.org/10.1037//0033-295X.109.3.573

Eagly AH, Steffen VJ (1984) Gender stereotypes stem from the distribution of women and men into social roles. J Pers Soc Psychol 46:735-754. https://doi.org/10.1037/0022-3514.46.4.735

Eagly AH, Wood W (2012) Social role theory. In: van Lange PAM, Kruglanski AW, Higgins ET (eds) Handbook of theories of social psychology. Sage Publications, Thousand Oaks, pp 458-476

Eagly AH, Nater C, Miller DI, Kaufmann M, Sczesny S (2020) Gender stereotypes have changed: a cross-temporal meta-analysis of U.S. public opinion polls from 1946 to 2018. Am Psychol 75:301315. https://doi.org/10.1037/amp0000494

Eddy M (2018) Not male or female? Germans can now choose 'diverse.' www.nytimes.com/2018/12/14/ world/europe/transgender-germany-diverse.html. Accessed 6 April 2021

Faul F, Erdfelder E, Lang AG, Buchner A (2007) G*Power 3: a flexible statistical power analysis program for the social, behavioral, and biomedical sciences. Behav Res Methods 39:175-191. https://doi.org/ $10.3758 / \mathrm{BF} 03193146$

Field A (2013) Discovering statistics using IBM SPSS statistics. Sage Publications, New York

Fowler SL, Geers AL (2017) Does trait masculinity relate to expressing toughness? The effects of masculinity threat and self-affirmation in college men. Psychol Men Masc 18:176-186. https://doi.org/10. $1037 / \mathrm{men} 0000053$

Gilbert DT (1991) How mental systems believe. Am Psychol 46:107-119. https://doi.org/10.1037/0003066X.46.2.107 
Gilmore DD (1990) Manhood in the making. Cultural concepts of masculinity. Yale University Press, New Haven \& London

Haselhuhn MP, Kray LJ (2012) Gender and negotiation. In: Goldman BM, Shapiro DL (eds) The psychology of negotiations in the 21st century workplace: new challenges and new solutions. Routledge/Taylor \& Francis Group, New York, pp 293-324

Haselhuhn MP, Wong EM, Ormiston ME, Inesi ME, Galinsky AD (2014) Negotiating face-to-face: Men's facial structure predicts negotiation performance. Leadersh Q 25:835-845. https://doi.org/10. 1016/j.leaqua.2013.12.003

Heilman ME, Wallen AS (2010) Wimpy and undeserving of respect: penalties for men's gender-inconsistent success. J Exp Soc Psychol 46:664-667. https://doi.org/10.1016/j.jesp.2010.01.008

Holland JL (1996) Exploring careers with a typology: what we have learned and some new directions. Am Psychol 51:397-406. https://doi.org/10.1037/0003-066X.51.4.397

Hüffmeier J, Krumm S, Hertel G (2011) The practitioner-researcher divide in psychological negotiation research: Current state and future perspective. Negot Confl Manag Res 4:145-168. https://doi.org/ 10.1111/j.1750-4716.2011.00077.x

Hüffmeier J, Freund PA, Zerres A, Backhaus K, Hertel G (2014) Being tough or being nice? A metaanalysis on the impact of hard-and softline strategies in distributive negotiations. J Manag 40:866892. https://doi.org/10.1177/0149206311423788

James W (1889) The psychology of belief. Mind 14:321-352. https://doi.org/10.1093/mind/XIV.55.321

Jones KP, Peddie CI, Gilrane VL, King EB, Gray AL (2016) Not so subtle: a meta-analytic investigation of the correlates of subtle and overt discrimination. J Manag 42:1588-1613. https://doi.org/10.1177/ 0149206313506466

Kalev A, Dobbin F, Kelly E (2006) Best practices or best guesses? Assessing the efficacy of corporate affirmative action and diversity policies. Am Sociol Rev 71:589-617. https://doi.org/10.1177/00031 2240607100404

Kennedy JA, Kray LJ (2015) A pawn in someone else's game? The cognitive, motivational, and paradigmatic barriers to women's excelling in negotiation. Res Organ Behav 35:3-28. https://doi.org/10. 1016/j.riob.2015.09.002

Koenig AM, Eagly AH (2014) Evidence for the social role theory of stereotype content: observations of groups' roles shape stereotypes. J Pers Soc Psychol 107:371-392. https://doi.org/10.1037/a0037215

Kong DT, Dirks KT, Ferrin DL (2014) Interpersonal trust within negotiations: meta-analytic evidence, critical contingencies, and directions for future research. Acad Manag J 57:1235-1255. https://doi. org/10.5465/amj.2012.0461

Kray LJ, Haselhuhn MP (2012) Male pragmatism in negotiators' ethical reasoning. J Exp Soc Psychol 48:1124-1131. https://doi.org/10.1016/j.jesp.2012.04.006

Kray LJ, Thompson LL (2005) Gender stereotypes and negotiation performance: an examination of theory and research. In: Staw BM, Kramer RM (eds) Research in organizational behavior: an annual series of analytical essays and critical reviews, vol 26. Elsevier Science/JAI Press, New York, pp $103-182$

Kray LJ, Thompson LL, Galinsky AD (2001) Battle of the sexes: gender stereotype confirmation and reactance in negotiations. J Pers Soc Psychol 80:942-958. https://doi.org/10.1037/0022-3514.80.6. 942

Kray LJ, Locke CC, Van Zant AB (2012) Feminine charm: an experimental analysis of its costs and benefits in negotiations. Pers Soc Psychol Bull 38:1343-1357. https://doi.org/10.1177/0146167212 453074

Kugler KG, Reif JAM, Kaschner T, Brodbeck FC (2018) Gender differences in the initiation of negotiations: a meta-analysis. Psychol Bull 144:198-222. https://doi.org/10.1037/bul0000135

Kulik CT, Olekalns M (2012) Negotiating the gender divide: lessons from the negotiation and organizational behavior literatures. J Manag 38:1387-1415. https://doi.org/10.1177/0149206311431307

Lee M, Pitesa M, Pillutla MM, Thau S (2017) Male immorality: an evolutionary account of sex differences in unethical negotiation behavior. Acad Manag J 60:2014-2044. https://doi.org/10.5465/amj. 2015.0461

Leslie LM (2019) Diversity initiative effectiveness: a typological theory of unintended consequences. Acad Manag Rev 44:538-563. https://doi.org/10.5465/amr.2017.0087

Leslie LM, Bono JE, Kim YS, Beaver GR (2020) On melting pots and salad bowls: a meta-analysis of the effects of identity-blind and identity-conscious diversity ideologies. J Appl Psychol 105:453-471. https://doi.org/10.1037/ap10000446 
Livingston BA (2014) Bargaining behind the scenes: spousal negotiation, labor, and work-family burnout. J Manag 40:949-977. https://doi.org/10.1177/0149206311428355

Manea CN, Demoulin S, Yzerbyt V (2020) Whatever you do, just don't let him notice you're a woman! General beliefs on women's gender ideology as a function of topic in mixed-gender negotiations. Int J Psychol. https://doi.org/10.1002/ijop.12714

Markóczy L (1997) Measuring beliefs: accept no substitutes. Acad Manag J 40:1228-1242. https://doi. org/10.5465/256934

Mazei J, Hüffmeier J, Freund PA, Stuhlmacher AF, Bilke L, Hertel G (2015) A meta-analysis on gender differences in negotiation outcomes and their moderators. Psychol Bull 141:85-104. https://doi.org/ $10.1037 / \mathrm{a} 0038184$

Mazei J, Zerres A, Hüffmeier J (2021) Masculinity at the negotiation table: a theory of men's negotiation behaviors and outcomes. Acad Manag Rev 46:108-127. https://doi.org/10.5465/amr.2017. 0570

Mazei J, Hüffmeier J (2021) Are women less likely to ask than men partly because they work fewer hours? A commentary on Artz et al. (2018). Meta-Psychology. Accessed 06 Apr 2021, from https://psyarxiv.com/avpmj/

Meeussen L, Van Laar C, Van Grootel S (2020) How to foster male engagement in traditionally female communal roles and occupations: insights from research on gender norms and precarious manhood. Soc Issues Policy Rev 14:297-328. https://doi.org/10.1111/sipr.12060

Miller DT, Taylor B, Buck ML (1991) Gender gaps: who needs to be explained? J Pers Soc Psychol 61:5-12. https://doi.org/10.1037/0022-3514.61.1.5

Miller J (2013) Unmasking masculinity in negotiation scholarship. Harvard negotiation law review. https://www.hnlr.org/wp-content/uploads/sites/22/2013/11/Miller-Unmasking-Masculinity-inNegotiation-Scholarship.pdf. Accessed 08 February 2021

Netchaeva E, Kouchaki M, Sheppard LD (2015) A man's (precarious) place: men's experienced threat and self-assertive reactions to female superiors. Pers Soc Psychol Bull 41:1247-1259. https:// doi.org/10.1177/0146167215593491

Nickerson RS (1998) Confirmation bias: a ubiquitous phenomenon in many guises. Rev Gen Psychol 2:175-220. https://doi.org/10.1037/1089-2680.2.2.175

Nishii LH, Khattab J, Shemla M, Paluch RM (2018) A multi-level process model for understanding diversity practice effectiveness. Acad Manag Ann 12:37-82. https://doi.org/10.5465/amr.2017. 0087

Recalde M, Vesterlund L (2020) Gender differences in negotiation and policy for improvement (working paper no. w28183). National Bureau of Economic Research. https://doi.org/10.3386/w28183

Ross L, Lepper M, Ward A (2010) History of social psychology: insights, challenges, and contributions to theory and application. In: Fiske ST, Gilbert DT, Lindzey G (eds) Handbook of social psychology, 5th edn. John Wiley \& Sons Inc., Hoboken, pp 3-50

Rudman LA (1998) Self-promotion as a risk factor for women: the costs and benefits of counterstereotypical impression management. J Pers Soc Psychol 74:629-645. https://doi.org/10.1037/0022-3514. 74.3.629

Rudman LA, Fairchild K (2004) Reactions to counterstereotypic behavior: the role of backlash in cultural stereotype maintenance. J Pers Soc Psychol 87:157-176. https://doi.org/10.1037/0022-3514.87.2. 157

Rudman LA, Phelan JE (2008) Backlash effects for disconfirming gender stereotypes in organizations. Res Organ Behav 28:61-79. https://doi.org/10.1016/j.riob.2008.04.003

Rudman LA, Moss-Racusin CA, Phelan JE, Nauts S (2012) Status incongruity and backlash effects: defending the gender hierarchy motivates prejudice against female leaders. J Exp Soc Psychol 48:165-179. https://doi.org/10.1016/j.jesp.2011.10.008

Rynes S, Rosen B (1995) A field survey of factors affecting the adoption and perceived success of diversity training. Pers Psychol 48:247-270. https://doi.org/10.1111/j.1744-6570.1995.tb01756.x

Shan W, Keller J, Imai L (2016) What's a masculine negotiator? What's a feminine negotiator? It depends on the cultural and situational contexts. Negot Confl Manag Res 9:22-43. https://doi.org/10.1111/ ncmr. 12065

Shan W, Keller J, Joseph D (2019) Are men better negotiators everywhere? A meta-analysis of how gender differences in negotiation performance vary across cultures. J Organ Behav 40:651-675. https:// doi.org/10.1002/job.2357

Simmons JP, Nelson LD, Simonsohn U (2012) A 21 word solution dialogue: the official newsletter of the society for personality and social. Psychology 26:4-7 
Small DA, Gelfand M, Babcock L, Gettman H (2007) Who goes to the bargaining table? The influence of gender and framing on the initiation of negotiation. J Pers Soc Psychol 93:600-613. https://doi.org/ 10.1037/0022-3514.93.4.600

Stuhlmacher AF, Linnabery E (2013) Gender and negotiation: a social role analysis. In: Olekalns M, Adair W (eds) Handbook of research on negotiation. Edward Elgar, London, pp 221-248

Stuhlmacher AF, Walters AE (1999) Gender differences in negotiation outcome: a meta-analysis. Pers Psychol 52:653-677. https://doi.org/10.1111/j.1744-6570.1999.tb00175.x

Swim JK, Hyers LL, Cohen LL, Ferguson MJ (2001) Everyday sexism: evidence for its incidence, nature, and psychological impact from three daily diary studies. J Soc Issues 57:31-53. https://doi.org/10. 1111/0022-4537.00200

Twenge JM (1997) Changes in masculine and feminine traits over time: a meta-analysis. Sex Roles 36:305-325. https://doi.org/10.1007/BF02766650

Vandello JA, Bosson JK (2013) Hard won and easily lost: a review and synthesis of theory and research on precarious manhood. Psychol Men Masc 14:101-113. https://doi.org/10.1037/a0029826

Vandello JA, Bosson JK, Cohen D, Burnaford RM, Weaver JR (2008) Precarious manhood. J Pers Soc Psychol 95:1325-1339. https://doi.org/10.1037/a0012453

Weaver JR, Vandello JA, Bosson JK, Burnaford RM (2010) The proof is in the punch: gender differences in perceptions of action and aggression as components of manhood. Sex Roles 62:241-251. https:// doi.org/10.1007/s11199-009-9713-6

Williams JC, Berdahl JL, Vandello JA (2016) Beyond work-life “integration.” Annu Rev Psychol 67:515539. https://doi.org/10.1146/annurev-psych-122414-033710

Wood W, Eagly AH (2010) Gender. In: Fiske ST, Gilbert DT, Lindzey G (eds) Handbook of social psychology, 5th edn. John Wiley \& Sons Inc., Hoboken, pp 629-667

Publisher's Note Springer Nature remains neutral with regard to jurisdictional claims in published maps and institutional affiliations. 